\title{
Functional diversity of the Barents Sea fish community
}

\author{
Magnus Aune Wiedmann ${ }^{1, *}$, Michaela Aschan ${ }^{1}$, Grégoire Certain ${ }^{2}$, Andrey Dolgov ${ }^{3}$, \\ Michael Greenacre $^{1,4}$, Edda Johannesen ${ }^{5}$, Benjamin Planque ${ }^{2}$, Raul Primicerio ${ }^{6}$ \\ ${ }^{1}$ Norwegian College of Fishery Science, University of Tromsø (UiT), 9037 Tromsø, Norway \\ ${ }^{2}$ Institute of Marine Research (IMR), PO Box 6404, 9294 Tromsø, Norway \\ ${ }^{3}$ Knipovich Polar Research Institute of Marine Fisheries and Oceanography (PINRO), 6 Knipovich Street, 183038 Murmansk, \\ Russia \\ ${ }^{4}$ Universitat Pompeu Fabra and Barcelona Graduate School of Economics, Ramon Trias Fargas 25-27, 08005 Barcelona, Spain \\ ${ }^{5}$ Institute of Marine Research (IMR), PO Box 1870, Nordnes, 5817 Bergen, Norway \\ ${ }^{6}$ Department of Marine and Arctic Biology, University of Tromsø (UiT), 9037 Tromsø, Norway
}

\begin{abstract}
This paper provides the first assessment of the functional diversity (FD) of the Barents Sea fish community. FD is recognized as an important driver of ecosystem functions and, thus, governs the adaptability of ecosystems in the face of disturbance. We integrate ecosystem survey data with an extensive trait matrix and show that fish FD displayed large spatial variation. The study period (2004 to 2009) was characterized by increasing water temperatures and decreasing ice coverage. FD remained stable between years in some areas but showed substantial variation in other areas. For instance, FD was consistently high in the central-west Barents Sea because of the high richness of functionally homogeneous species, whereas it varied strongly in northern areas through time. Such patterns of strong variation were probably driven by the strong warming trend registered in the study period. The species found in the eastern Barents Sea were more functionally distinct than those found in the west. Even though this pattern indicates that assemblages in the eastern areas display high adaptability relative to the number of species present, species loss in these areas will have a higher impact on the FD. Our findings show that FD gives more information about fish community structure and functioning than traditional biodiversity measures, and we suggest that such trait-based methods may constitute useful tools for future monitoring and management of marine fish communities.
\end{abstract}

KEY WORDS: Biodiversity $\cdot$ Functional traits $\cdot$ Functional dispersion $\cdot$ Fish $\cdot$ Monitoring

\section{INTRODUCTION}

Northern marine ecosystems are experiencing major ecological alterations driven by environmental change associated with climate warming and fisheries (Overland \& Stabeno 2004, Brander 2007, Bundy et al. 2009). To understand ongoing ecological change and manage marine ecosystems sustainably, reliable assessments of their functioning and vulnerability are necessary (Levin \& Lub- chenco 2008). The vulnerability of ecosystems to environmental perturbations depends on their adaptability, i.e. their ability to maintain functions under changing conditions (IPCC 1996, Walker et al. 1999). Biodiversity promotes ecosystem adaptability, as the number of functions performed within an ecosystem increases with the number of species, as well as its buffering capacity through functional redundancy (Loreau et al. 2001, Levin \& Lubchenco 2008). 
Different measures of biodiversity have been proposed. In its simplest form, biodiversity has been defined as species richness (SR), i.e. the number of species in an ecosystem. Although such a measure of taxonomic diversity is relatively easy to obtain, it does not account for the functional variation between taxonomic units. Species attributes should be taken into account when studying diversity-functioning relationships. Phylogenetic diversity (PD) implicitly accounts for diversity in species attributes by recognizing that phylogenetically distant species contribute more to diversity than closely related species, reflecting the 'tree of life' (Mace et al. 2003). To account explicitly for diversity of biological attributes, measures of functional diversity (FD) have recently been developed (Petchey \& Gaston 2006). In this way, the assumption that all species contribute equally to biodiversity is moderated. FD is defined as the range and value of those species and organismal traits that influence ecosystem functioning (Tilman 2001). Various ways to calculate FD have been proposed; an early approach considered functional group richness (e.g. Tilman et al. 1997), but continuous measures have also been introduced (Petchey \& Gaston 2002, Villéger et al. 2008, Laliberté \& Legendre 2010).

The above FD measures have been applied in plant community studies in particular, and the results suggest that FD is an indicator of ecosystem resource dynamics, productivity and stability (Díaz \& Cabido 2001). FD measures also allow for the assessment of functional dispersion in a community, i.e. the degree of functional traits' heterogeneity among community members (Mouillot et al. 2007, Devictor et al. 2010). Functional dispersion, which can be defined as the deviations from a model (i.e. the residuals) describing the relationship between FD (the response) and SR (the predictor), can be regarded as a measure of 'net' FD (Devictor et al. 2010). For a given number of species, assemblages with higher functional trait dispersion (i.e. overdispersion) are expected to result in greater ecosystem adaptability, but they will also show greater vulnerability since any species loss will result in the loss of more functions. High functional dispersion is promoted by ecological processes and environmental conditions that enhance differentiation among coexisting species, such as interspecific competition, favoring of niche segregation, or environmental heterogeneity, selecting for species adapted to different habitats. FD is now widely accepted as a key driver of ecosystem functioning (Hooper et al. 2005). However, measuring the FD in marine environments is a challenging task because of the cost of collecting data and the lack of information on functional traits. Thus, only a few studies have focused on FD in marine fish communities (e.g. Halpern \& Floeter 2008, Stelzenmüller et al. 2009, Martins et al. 2012).

Based on ecosystem survey fish data (Johannesen et al. 2012a) and an extensive functional trait matrix, we provide the first estimates of FD for the fish community of the Barents Sea. This paper has 3 objectives: (1) to assess the spatio-temporal variation in Barents Sea fish FD, (2) to interpret the observed variation in the FD on the basis of biological and environmental explanatory factors, and (3) to assess potential implications of the observed FD patterns for adaptability and vulnerability of the fish community.

\section{MATERIALS AND METHODS}

\section{Study area}

The Barents Sea is a relatively shallow (average depth $230 \mathrm{~m}$ ) shelf sea area in the northeastern Atlantic delimited by the Norwegian and Russian coasts in the south, Novaya Zemlya in the east, the shelf break to the Atlantic Ocean in the west and the shelf break to the Arctic Ocean in the north (Fig. 1). The climate in the Barents Sea is to a large degree governed by the inflow of Atlantic water masses (Loeng 1991). Two currents, the Norwegian Coastal Current (NWCC) and the Norwegian Atlantic Current (NWAC), flow northward along the Norwegian coast. While the NWCC continues eastward towards Russian waters, where it is renamed the Murman Coastal Current, the NWAC continues northward along the shelf break and bifurcates into the northward-flowing West Spitsbergen Current and the eastward-flowing North Cape Current.

The Barents Sea is a highly productive area where typical annual fisheries yields vary between 0.5 and 4.5 million tons (Nakken 1998). Of the 200 fish species known to occur in the Barents Sea, about 100 are commonly observed during research surveys.

\section{Fish distribution data}

Fish were sampled on board Norwegian (Institute of Marine Research) and Russian (Knipovich Polar Research Institute of Marine Fisheries and Oceanography) vessels in August-September 2004 to 2009. The gear used was the Campelen 1800 shrimp trawl, and the standard trawling time was 15 min at 3 knots 


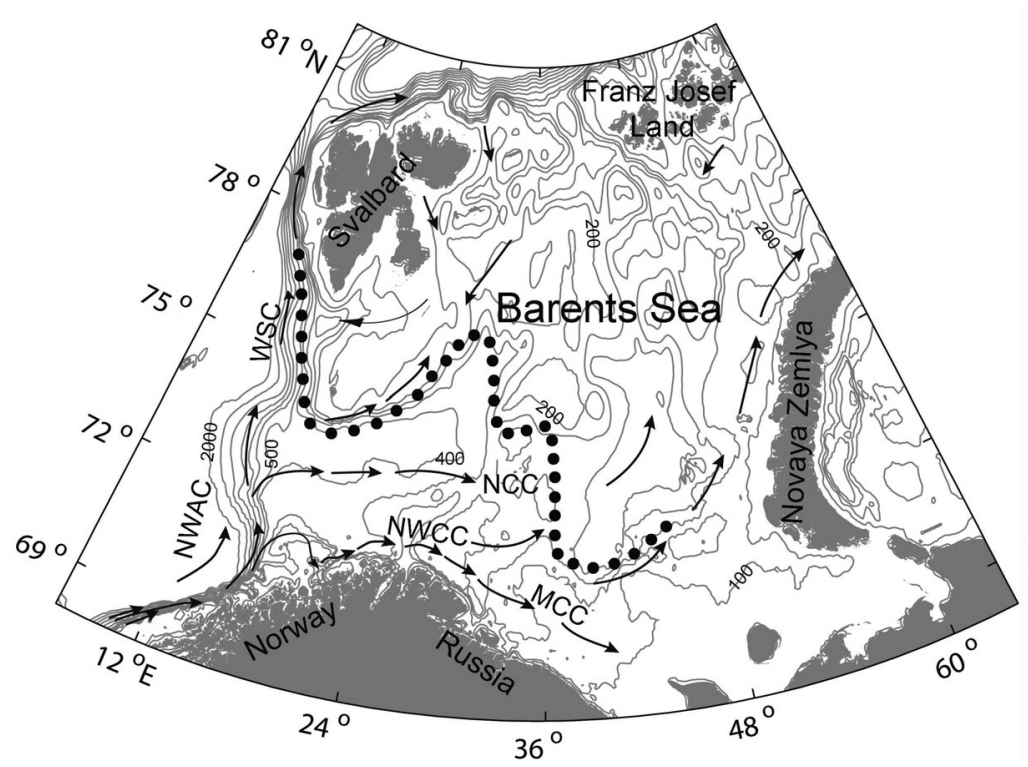

Fig. 1. Barents Sea. Arrows indicate direction of surface currents. Dominant currents in the area are the Norwegian Atlantic Current (NWAC), the Norwegian Coastal Current (NWCC), the North Cape Current (NCC), the West Spitsbergen Current (WSC) and the Murman Coastal Current (MCC). Dotted line $(\bullet \bullet)$ is the mean position of the polar front. Depths are given in meters

(0.75 nautical mile). The joint Norwegian-Russian ecosystem surveys are described by Wienerroither et al. (2011). All stations deeper than $500 \mathrm{~m}$ and shallower than $50 \mathrm{~m}$ were removed from the analyses. A total of 1901 stations were retained for final analyses. In total, 98 fish species were caught from 2004 to 2009. Although the number of trawled stations varied between years (between 319 in 2009 and 546 in 2005), the total number of species (SR) found each year in the Barents Sea did not vary much (between 66 in 2005 and 73 in both 2008 and 2009). Species that were absent in more than 2 yr or only caught off the chosen depth range (50 to $500 \mathrm{~m}$ ) were removed from the analyses $(n=21)$. Because of uncertainties regarding species identification, a few species were identified only to genus level $(\mathrm{n}=3)$. The final species list included 77 fish taxa. SR per station varied between 1 and 21. We define the 'fish community' as all fish found in the Barents Sea, whereas we define 'fish assemblage' as the pool of species found at each specific station.

\section{Functional traits}

The functional traits used in this study were carefully chosen to mirror relevant aspects of ecosystem functioning (Table 1). Ecosystem functioning is here mainly related to the flow of energy and material (e.g. organic matter). Examples of functional interpretations for each trait are provided in the 'Ecosystem function' column (Table 1), but the list is not exhaustive, as each functional trait can be interpreted in terms of several ecosystem functions. The traits matrix consisted of 27 functional traits belonging to 7 trait categories. Species traits were obtained from a comprehensive literature survey (see Supplement 1, Table S1 for the full trait matrix and Table S2 for citations, and Supplement 2 for references to the trait matrix documentation, available at www.int-res.com/ articles/suppl/m495p205_supp/). In cases where trait information was lacking in the literature $(\mathrm{n}=23)$, values were inferred based on knowledge about closely related species.

Species diet (benthivorous, planktivorous and/or piscivorous) provides information about feeding links and thereby food web structure. The diet also reflects the degree of omnivory in a given species assemblage, thereby reflecting its capacity to adapt and restructure in the face of disturbance. Species habitat relates to the coupling between habitat types, indicating what type of production a species preys upon (pelagic and/or benthic/demersal). Such coupling is important for the flow of energy and material between various habitats at a given location. Although some species appear to thrive both in the pelagic and demersal zones, many species are either pelagic or demersal.

The location of newly spawned eggs or larvae (demersal, planktonic or ovoviviparous/freely swimming) relates to paths of energy and material flow. Eggs and larvae transfer energy to higher or lower trophic levels if they are eaten, and they use the energy for growth, determining the type of new production that is transferred towards higher trophic levels.

Also, fecundity (mean number of offspring female f $^{-1}$ $\mathrm{yr}^{-1}$ ) and eggs or larvae size (large [>8 mm], medium [2-8 mm] or small $[<2 \mathrm{~mm}]$ ) are related to the flow and allocation of energy and material, as well as production rates in the system. For instance, a combination of these 4 traits describes the degree of eggs and larvae dispersal and thereby the degree to which they are locally retained. Eggs and larvae sizes are here referred to as the size in millimeters at the moment they are released from the parent (egg dia- 
Table 1. Overview of functional traits included in the analyses. Variables were binary except fecundity and asymptotic length, which were continuous

\begin{tabular}{|c|c|c|}
\hline Trait category & Ecosystem function & Trait \\
\hline Diet & $\begin{array}{l}\text { Food web structure, energy and material flow } \\
\text { between species }\end{array}$ & $\begin{array}{l}\text { Benthivorous } \\
\text { Planktivorous } \\
\text { Piscivorous }\end{array}$ \\
\hline Habitat & Benthic-pelagic coupling & $\begin{array}{l}\text { Pelagic } \\
\text { Demersal }\end{array}$ \\
\hline Offspring behaviour & Paths of energy and material flow & $\begin{array}{l}\text { Demersal } \\
\text { Planktonic } \\
\text { Ovoviviparous; freely swimming }\end{array}$ \\
\hline $\begin{array}{l}\text { Fecundity and } \\
\text { offspring size }\end{array}$ & $\begin{array}{l}\text { Production rate and energy allocation } \\
\text { in the ecosystem }\end{array}$ & $\begin{array}{l}\text { Fecundity } \\
\text { Large offspring } \\
\text { Medium offspring } \\
\text { Small offspring }\end{array}$ \\
\hline Fish size & $\begin{array}{l}\text { Food web structuring. Storage and accumulation } \\
\text { of energy. Turnover rates }\end{array}$ & Asymptotic length \\
\hline Body shape & $\begin{array}{l}\text { Sediment resuspension and release of material. } \\
\text { Paths of energy and material flow. Energy allocation }\end{array}$ & $\begin{array}{l}\text { Flat } \\
\text { Eel-like } \\
\text { Normal } \\
\text { Elongated } \\
\text { Short/deep }\end{array}$ \\
\hline Tolerance range & $\begin{array}{l}\text { Combination of tolerance range and body shape } \\
\text { influences the availability of imported energy }\end{array}$ & $\begin{array}{l}\text { Highly temperature tolerant } \\
\text { Moderately temperature tolerant } \\
\text { Not temperature tolerant } \\
\text { Highly salt tolerant } \\
\text { Moderately salt tolerant } \\
\text { Not salt tolerant } \\
\text { Highly depth tolerant } \\
\text { Moderately depth tolerant } \\
\text { Not depth tolerant }\end{array}$ \\
\hline
\end{tabular}

meter, capsule length or larvae length). The fecundity data were log-transformed.

Fish asymptotic length $(\mathrm{cm})$ is a measure of how large an individual of a given species is expected to become. Fish length is related to numerous ecosystem functions such as food web structuring (size affects prey-predator relationships) and energy storage and accumulation (larger organisms store and require more energy). In cases where the asymptotic length $\left(L_{\infty}\right)$ was not available, maximum lengths described in the literature $\left(L_{\max }\right)$ were used. Although they may differ, $L_{\infty}$ and $L_{\max }$ are usually strongly correlated (Froese \& Binohlan 2000). The fish length data were log-transformed.

Body shape data were obtained from www.fishbase.org (Froese \& Pauly 2011) and divided into 5 categories: normal, flat, eel-like, elongated and short/deep. Body shape reflects many functionally relevant aspects of the ecology of an organism (Wainwright 1994). For instance, the body shape sets restrictions as to what type of habitat a species will likely utilize as well as its migration capability.
The species' environmental ranges (tolerance range in temperature, salinity and depth) were calculated based on the ecosystem survey data, and they describe the species' potential to import energy and material from areas that differ in terms of these environmental factors. The tolerance range for each environmental factor was divided into 3 categories based on tolerance ranges in absolute values, independent of the species' actual depth preferences (Table S1). A combination of body size, body shape and environment tolerance can be related to migration capability and thereby energy and material transfer, e.g. how far the species in the community travel and the probability that they will remain in (or return to) the area despite disturbance. Also, strongly migratory species are able to travel far to import new energy and material, whereas weakly migratory species can be better at exploiting local resources. To account for the fact that some traits were related (thereby entailing unequal weighting between trait types), each trait category was equally weighted, and this weight was shared equally by all traits within that specific trait category. 


\section{Measuring functional diversity}

We calculated FD according to the dendrogrambased approach developed by Petchey \& Gaston (2002, 2006). Measuring FD in space involved a 4-step process (Fig. 2). (1) We constructed the databases on functional traits (trait matrix based on literature survey) and on spatial distribution (a presence/ absence matrix based on ecosystem survey data). The presence of species provides information about the capacity of the fish community to perform a certain diversity of functions and thereby the potential of the community to adapt. Therefore, we have chosen to apply the ecosystem survey data by means of presence/absence. (2) A distance method was used to calculate the interspecies dissimilarities in trait space. Because the trait matrix consisted of mixed variables (binary and continuous), the Gower distance measure (Gower 1971) was chosen. (3) The species were clustered into a dendrogram based on their dissimilarities in trait space (Fig. 3) by the unweighted pair group method using arithmetic averages, a recommended clustering method (Podani \& Schmera 2006) that, when compared with several alternatives, performed best on our data with regard to cophenetic correlation, a measure of how well the original dissimilarity structure is reflected by the dendrogram (Blackburn et al. 2005, Podani \& Schmera 2006). Given the resulting dendrogram, the total branch length of the dendrogram was calculated and used as a measure of FD of the regional species pool. (4) Based on the dendrogram, we calculated the branch length needed to connect all species found at each station. In this way, we measured station-level FD, excluding stations with less than 2 species, for which FD measures cannot be obtained.

1)

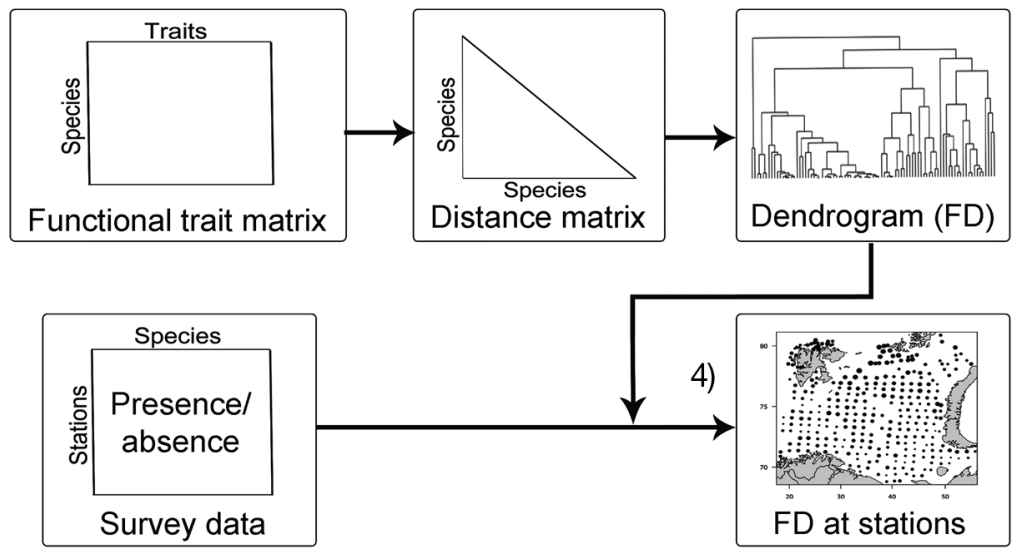

Fig. 2. Procedure for calculating functional diversity (FD). See main text for further details
Sensitivity analyses were carried out to assess the impact of individual species and traits on FD estimates. In the former case, the FD for all assemblages ( $\mathrm{n}=1901$ ), dropping one species at the time, was computed using the original dendrogram. In the latter case, different ways of coding and analyzing subsets of the trait matrix were investigated, each generating different dendrograms.

\section{Relationship between functional diverstiy, species richness and phylogenetic diversity}

The relationship between FD and SR was explored by linear regression. Because of the limited number of traits, a non-linear relationship between FD and SR could be expected (Petchey \& Gaston 2006). To investigate if such a non-linear relationship existed, we used a generalized additive model (GAM). The relationship was weakly non-linear. Since a linear regression accounted for nearly the same amount of variation as the non-linear relationship $\left(\mathrm{R}_{\text {linear }}^{2}=0.861 \mathrm{vs} . \mathrm{R}_{\text {non-linear }}^{2}=0.868\right)$, linear regression was used for subsequent analyses. We also estimated PD (Faith 1992, Clarke \& Warwick 1998), defined as the total length of all phylogenetic branches required to span a given set of taxa on the phylogenetic tree (Faith 1992). PD was based on 6 taxonomic ranks: species, genus, family, order, class and superclass. We calculated functional dispersion as the residuals from the regression between FD and SR. The FD residuals were further regressed on the $\mathrm{PD}$ residuals against SR to assess the relationship between functional dispersion and phylogenetic dispersion, having corrected for SR. To analyze the influence on FD of the potential drivers year, temperature, depth and SR, we used a general linear model correcting for spatial dependences by introducing geographical coordinates and associated polynomial terms.

\section{Spatial modelling}

To visualize variables such as FD, PD and SR on the Barents Sea map, we used universal kriging (Cressie 1993) based on a Gaussian variogram model. Spatial predictions were binned into a $50 \times 50 \mathrm{~km}$ grid system, leading to estimated means and standard deviations. 


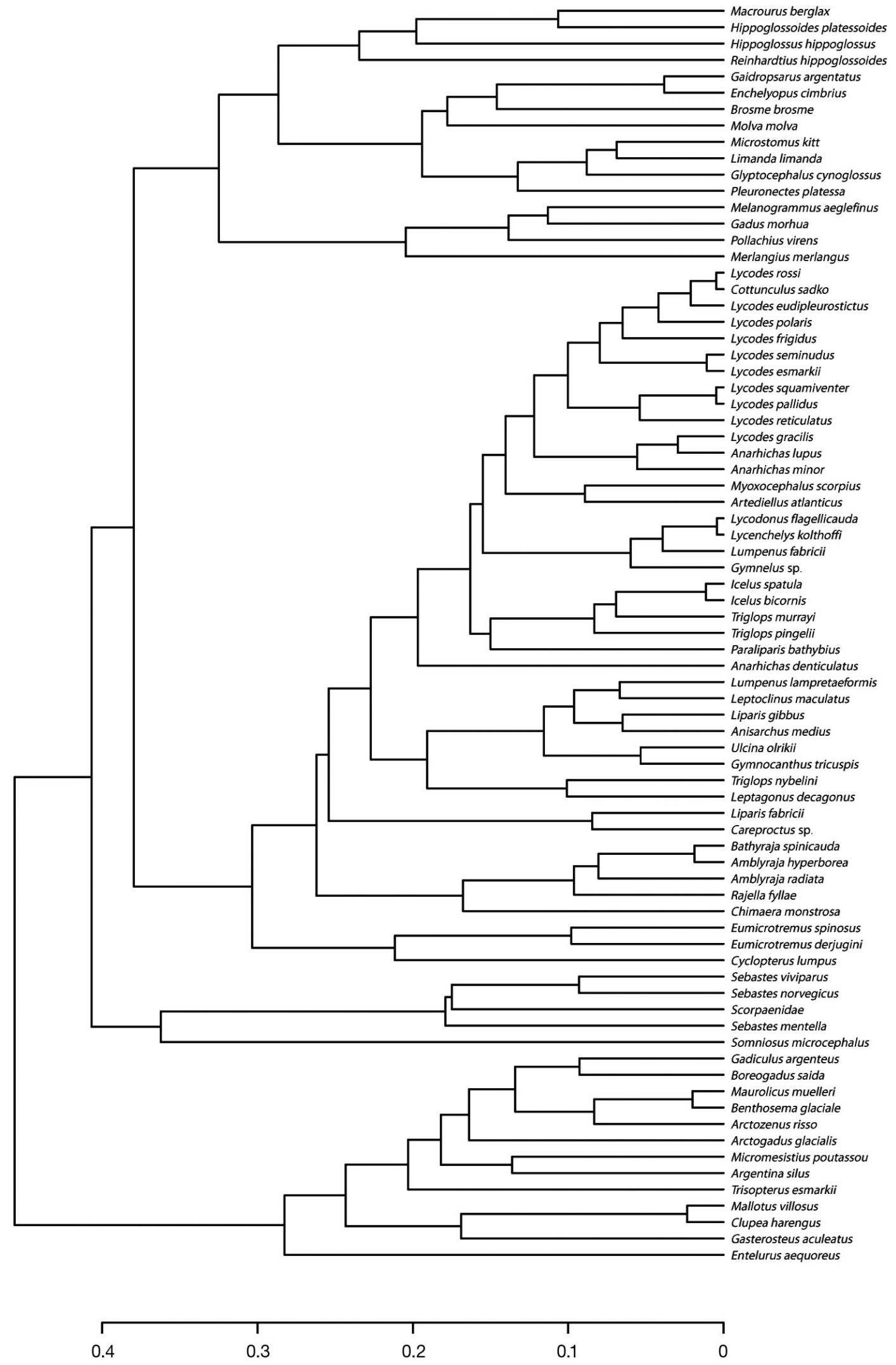

Fig. 3. Functional dendrogram of the relationships in trait space between 77 fish species found in the Barents Sea 


\section{Null model}

To investigate whether Barents Sea fish assemblages have higher FD than expected from a random assembly of species, we compared the observed FD with those of fish assemblages generated by a null model. Under the null model, compositional data were generated by random sampling of species from the Barents Sea fish species pool. The SR of randomly generated fish assemblages ranged between 2 and 21 (the maximum SR observed in our data). For a given number of species, 1000 random assemblages were generated and their FD was calculated, resulting in a total of 20000 FD values. To test for differences in FD between the data and the null model, we used a general linear model of FD as a function of the null model versus observed data, with SR as a covariate.

All analyses and simulations were performed using R software, version 2.15.1 (R Development Core Team 2012), and the packages vegan for FD and PD estimation (Oksanen et al. 2011), mgcv for GAM estimation (Wood 2000), gstat for spatial modelling (Pebesma \& Wesseling 1998) and maptools (LewinKoh \& Bivand 2012) and fields (Furrer et al. 2012) for mapping.

\section{RESULTS}

\section{Functional diversity in space and time}

Throughout the study period, regions of high FD were observed in central areas and off the Norwegian coast in the southwestern Barents Sea (Figs. 4 \& 5A,B), whereas a low-FD area was identified in the southeast. Some areas showed clear interannual variation in FD, particularly the northeasternmost parts of the Barents Sea as well as a transition zone between the central and southeasternmost regions. We also identified a transition zone between the far southwest and central-west where FD was low throughout the study period; this transition zone broadened in warm years. Also, the extent of the central high-FD area showed major interannual variation, expanding to the south in 2005, to the north in 2008 and in both directions in 2007 and 2009.

Average patterns in FD, PD and SR showed the highest values in the central areas and the lowest in the southeast (Fig. 5A,C,E). They also showed the greatest between-year variation in the north and northeast, as well as in the transition zone between the central and southeasternmost regions (Fig. 5B,D,F).

\section{Functional dispersion}

FD was higher in the Barents Sea data than in the null model $(p<0.0001)$. This implies that the Barents Sea fish assemblages had a higher overall functional dispersion (FD corrected for SR) than expected under a random assembly of species. Functional dispersion was consistently high in the cold central-east and low in the warm western slope areas south of the polar front (Fig. 6). Functional dispersion was also relatively low in the north, also in those years when FD increased in that area. The model of functional dispersion in terms of temperature, depth and spatial position (coded as a thirddegree polynomial) explained $20 \%$ of the variance. Although temperature has a highly significant bivariate correlation with functional dispersion $(\mathrm{r}=$ $-0.273, \mathrm{p} \approx 0.000$ ), its effect is diminished in the model when including the spatial covariates (estimated marginal effect of 0.01 reduction in functional dispersion per $1^{\circ}$ increase in temperature, standardized regression coefficient $=-0.074, \mathrm{p}=0.064)$. Also, functional dispersion increased significantly with water depth (estimated marginal effect of 0.02 increase in functional dispersion per $100 \mathrm{~m}$ increase in depth, standardized regression coefficient = 0.084, $\mathrm{p}=0.003)$. A systematic reduction in functional dispersion was observed from 2004 until 2008, whereas a weak increase was observed from 2008 to 2009. Functional dispersion was significantly lower in every year from 2006 to 2009 than in 2004 ( $\mathrm{p}<0.05$ in all cases).

FD (Fig. 5A) and PD (Fig. 5C) displayed similar spatial patterns. After correcting for the influence of $\mathrm{SR}$, there was a positive relationship between functional and phylogenetic dispersion $(r=0.786)$.

\section{DISCUSSION}

\section{Functional diversity in space and time}

The most prominent and persistent spatial patterns in the Barents Sea fish FD are associated with environmental features known to influence biodiversity. For instance, the high FD in the central-western area is associated with mixed water just south of the polar front, an area with high productivity (Dolgov et al. 2010), whereas the low FD in the southeast could be 

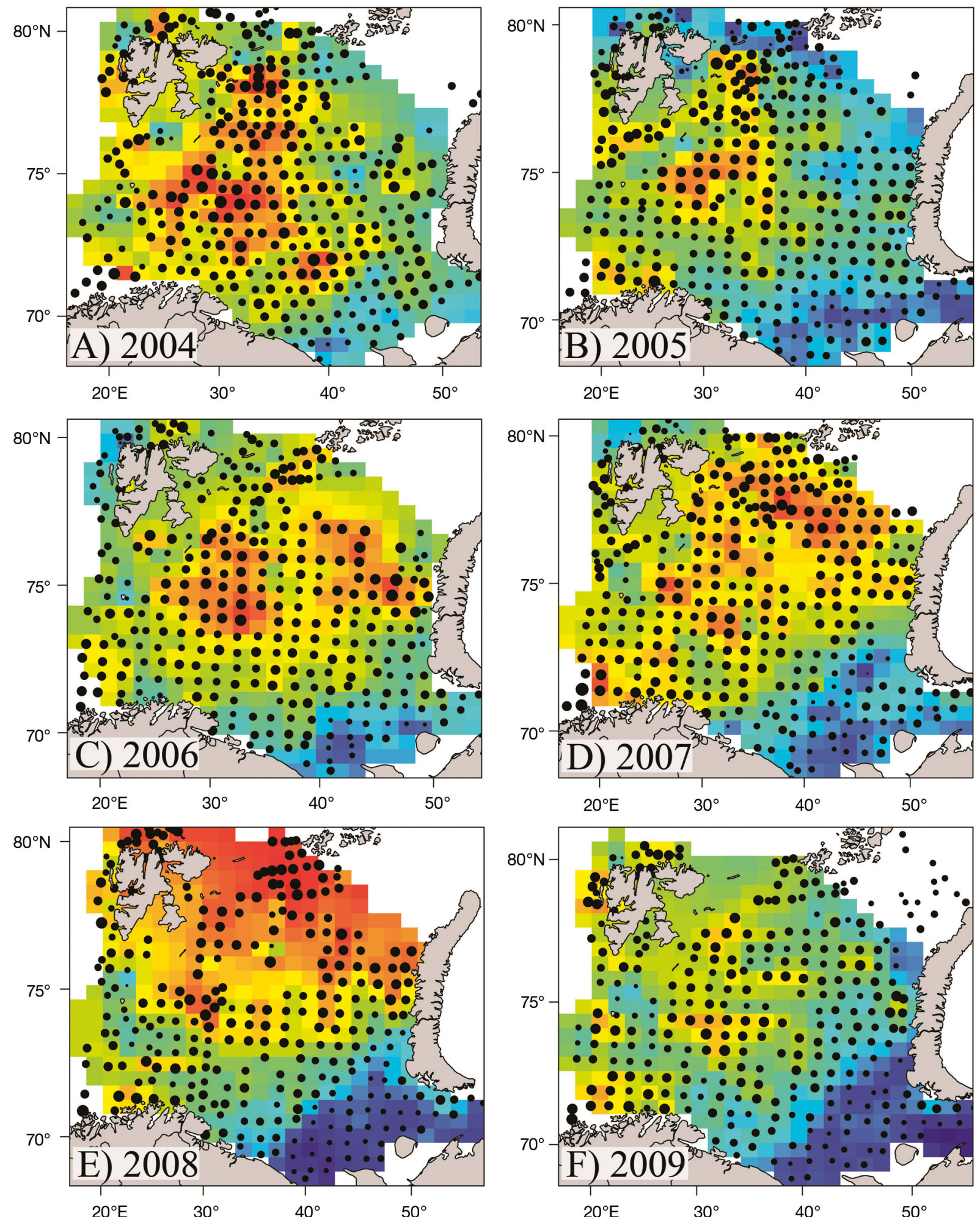

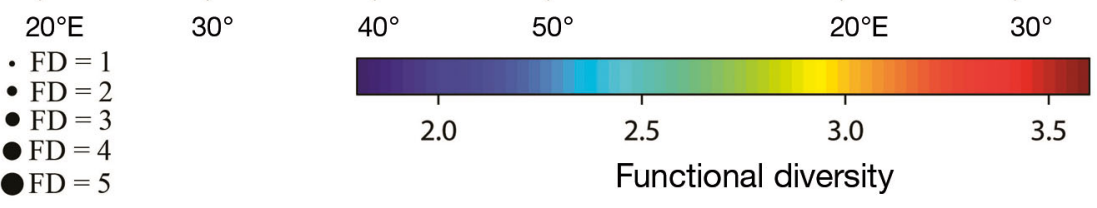

Fig. 4. Functional diversity (FD) of the Barents Sea fish community, 2004 to 2009. Circle sizes indicate FD at survey stations 

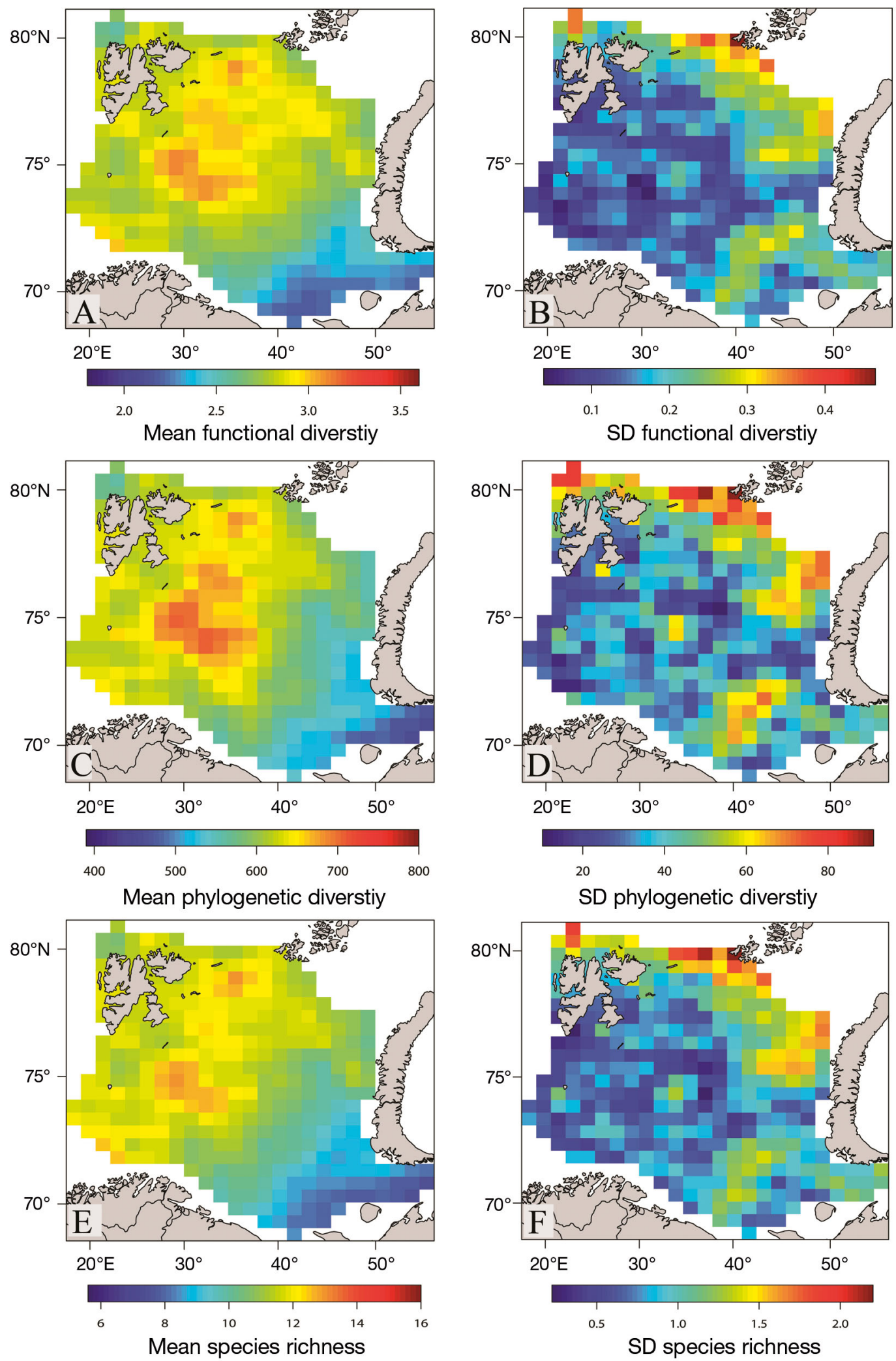

Fig. 5. Mean and standard deviation of functional diversity (FD), phylogenetic diversity (PD) and species richness (SR) in the Barents Sea fish community, 2004 to 2009 

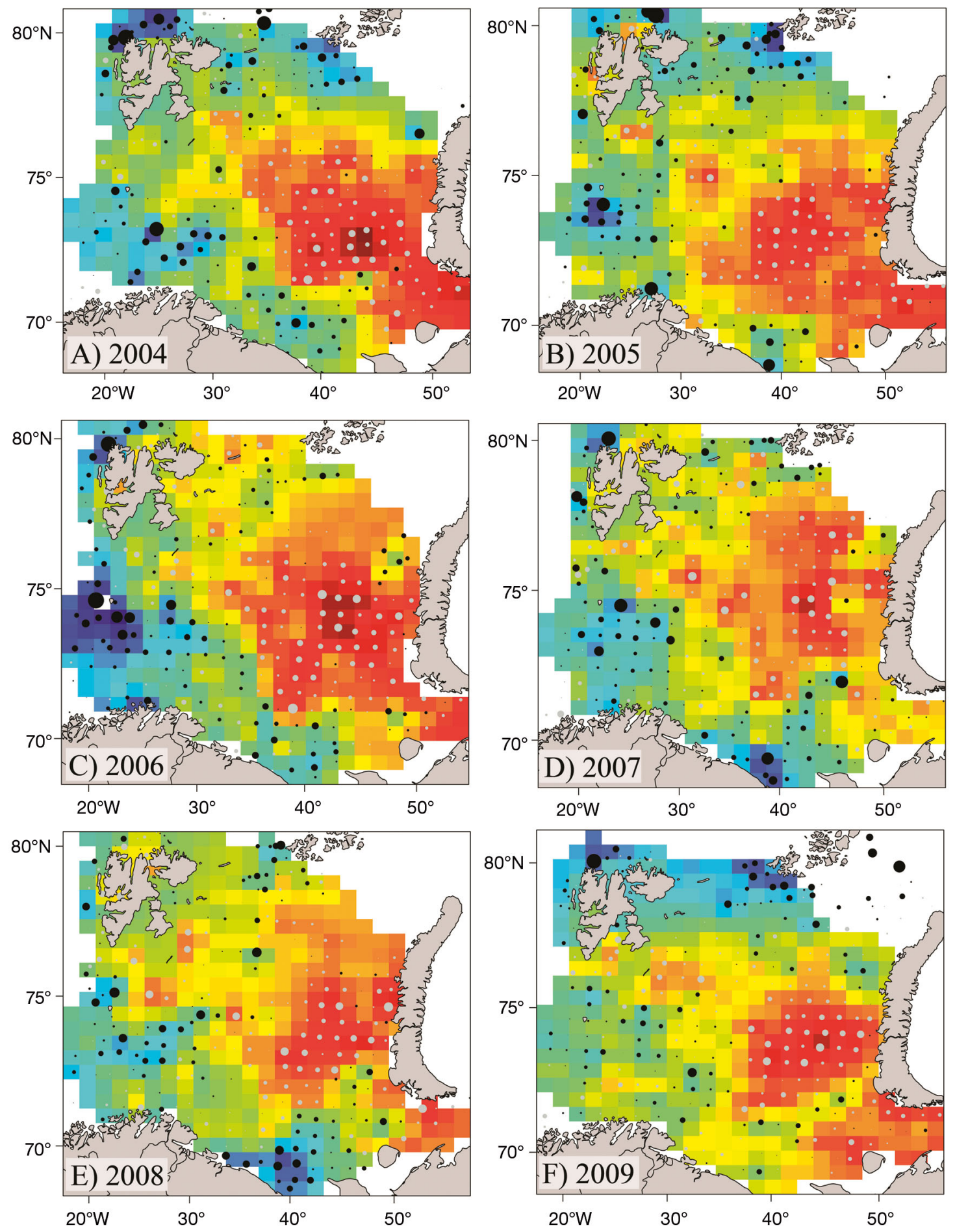

$$
\begin{aligned}
& \begin{array}{l}
=-0.9 \\
=-0.6
\end{array} \\
& \text { - }=-0.2 \\
& \begin{aligned}
= & =0.2 \\
& =0.6
\end{aligned} \\
& =0.9
\end{aligned}
$$

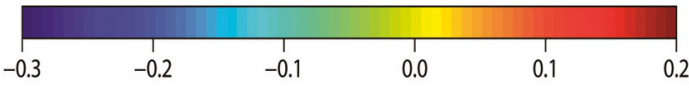

\section{Functional dispersion}

Fig. 6. Functional dispersion of the Barents Sea fish community during 2004 to 2009, calculated as the residuals from the linear regression of functional diversity (FD) on species richness (SR). Circle size corresponds to value. Red colors indicate positive dispersion (FD is higher than predicted from SR); blue colors indicate negative dispersion (FD is lower than predicted from SR) 
expected from the low SR there and from the proximity to the species-poor Arctic waters in the adjacent Kara Sea further east (Zeller et al. 2011, Johannesen et al. 2012a). Among the spatial FD patterns undergoing interannual change, 3 were particularly outstanding: the extent of the central high-FD area, the extent of the southeastern low-FD area and the variation in the north-northeast. In a long-term perspective, the entire study period, 2004 to 2009, was characterized by warm water, but within this period, the water was coldest in 2004 to 2005 and warmest in 2007 to 2008 (Johannesen et al. 2012b). In the first 2 yr (2004 to 2005), the central high-FD area was limited in size, whereas the FD in the north was low. In the warmer years, 2007 to 2008, when the sea ice extent was at its lowest (Wadhams 2012) and the icefree seasons were among the longest ever recorded (Rodrigues 2009), the central high-FD area was much larger, extending in both northern and southern directions and leading to relatively high FD in the northernmost areas. These extensions of the central high-FD area appeared to coincide with extensions of the southeastern low-FD area and vice versa, which are probably reflections of the variation in strength and direction of inflowing Atlantic water masses (Loeng 1991 and citations therein). Northern extensions of the high-FD area can thereby probably be related to changes in temperature and ice cover conditions. A steady increase in Atlantic and mixed water masses at the expense of Arctic water masses occurred during the last decade in the Barents Sea (Johannesen et al. 2012b). Furthermore, given recent trends in sea ice distribution, ice-free summers in the Arctic within the next $30 \mathrm{yr}$ are predicted (Wang \& Overland 2009). These conditions entail that spatial FD patterns similar to those seen in 2007 to 2008 are likely to occur more commonly in the years ahead.

There are major fisheries activities in the Barents Sea, and some of the most important fishing grounds are found in the west (Olsen et al. 2007), where we also find the FD to be persistently high. Thus, assuming that FD promotes ecosystem adaptability (Levin \& Lubchenco 2008), the fish assemblages in this area appear to maintain high levels of adaptability despite continual disturbance. This may be explained by the relatively high primary production in the rather persistent polar front area, as well as the proximity to the Norwegian Sea. On the contrary, the FD as well as the PD was very low in southeastern areas far from the Norwegian Sea, a pattern that was expected, as recent investigations showed that the fish assemblages in this area mainly consist of only 5 species (Johannesen et al. 2012a).

\section{Functional diversity, phytogenetic diversity and species richness}

A large proportion of the observed variation in FD was accounted for by SR. Spatial patterns of fish diversity in the Barents Sea were described by Johannesen et al. (2012a). In general, central and western areas show high species diversity; southeastern areas show lower diversity, whereas northern parts display greater variation. The relationships between FD, PD and SR are emphasized by our maps of interannual mean and standard deviation (Fig. 5). Indeed, FD, PD and SR are complementary biodiversity metrics (Flynn et al. 2009, Devictor et al. 2010). For instance, the close correlation between FD and PD indicates that these 2 measures carry similar information. Yet, we also observed discrepancies between spatial patterns of FD and SR that stress the importance played by functional dispersion in determining spatial variation in the Barents Sea fish FD. In other systems, the correlation between FD and SR ranged from 0.06 to 0.71 (Blackburn et al. 2005, Micheli \& Halpern 2005, Devictor et al. 2010), placing our case at the upper limit of this range. The strong relationship between FD and SR in our study is partly because of the low fish SR of the Barents Sea, which determines a strong influence on FD of each additional species found. Yet, despite our extensive review of the literature and of all the resources available, most of the documented traits are expressed in relatively simple, low-detailed units because of a lack of quantitative information. This is particularly true for the Arctic species. There is generally a clear need for further systematic studies of behavioral, life history and morphological traits of fish to improve measures of FD.

The close overall relationship between FD and SR could be used as an argument for the use of SR or another traditional diversity metric rather than FD when studying fish communities. Simple measures of diversity are easier to obtain, and they are not affected by methodological issues such as trait selection and the choice of FD algorithms. Also, explicit links between FD and certain ecosystem processes, such as those demonstrated in vegetation studies (e.g. Tilman et al. 1997), appear to be more challenging to identify in large marine systems. However, a recent study comprising 25 marine fish communities showed that the removal of even a small number of species by harvesting would lead to substantial FD loss (Martins et al. 2012). Likewise, the FD was shown to be highest close to a marine protected area in the northwestern Mediterranean (Stelzenmüller et 
al. 2009). More importantly, as we demonstrate in this paper, the joint use of SR and FD allows for extraction of functional dispersion, which is the component of FD that is independent from the number of species and allows for refined ecological interpretation of FD patterns. Similar findings have been made in terrestrial systems (Devictor et al. 2010) that highlight the importance of not being restricted to one single aspect of biodiversity.

\section{Functional dispersion and contribution of species to functional diversity}

Assessing functional dispersion provides further information on the functional characteristics of local assemblages. Assemblages may functionally be either overdispersed or underdispersed. In an overdispersed assemblage, the FD is higher than predicted from the number of species present. We can thus expect that an overdispersed assemblage will have relatively high adaptability because of the relatively high number of functions represented, but it will also be sensitive to species loss since each species likely has a high impact on FD. Overdispersion may call for special caution in the ecosystem management of such areas, especially if the FD is already low. Conversely, an underdispersed assemblage will have comparatively low adaptability considering the number of species present, but it will also be expected to be relatively insensitive to species loss since several species in such assemblages play similar functional roles in the ecosystem. In the face of disturbance, an underdispersed assemblage with a high FD can thus be expected to be both adaptable and insensitive to species loss.

The eastern Barents Sea consistently showed functional overdispersion, whereas the western Barents Sea showed functional underdispersion. This means that with regard to the functional traits considered, species were more different from each other in the east than in the west. Underdispersion is often related to environmental adversity (e.g. abiotic stress), whereas overdispersion is associated with competition (Weiher \& Keddy 1995). For instance, under strongly selective environments, the species present may be required to have some common functional features to survive (thereby causing underdispersion), whereas competing species cannot co-exist if they are too similar (thereby leading to overdispersion). This suggests that fish species composition could be most influenced by environmental stress in the west and by competition in the east. Most of the western areas, where underdispersion was observed, are characterized by inflowing Atlantic water masses. In contrast, the eastern area, where overdispersion was observed, is a transition zone consisting of 3 different water masses: warm Atlantic water, transformed Barents Sea water and cold Novaya Zemlya coastal water (Ozhigin et al. 2011). Therefore, a likely cause of overdispersion in the east could be a strong environmental heterogeneity rather than competition promoted by a more stable environment. Typical species found in the eastern area were capelin Mallotus villosus, Atlantic poacher Leptagonus decagonus and thorny skate Amblyraja radiata, species that are very different from each other in terms of functional traits. Because of the functional overdispersion, the FD remains rather high although SR is low.

The functional dispersion is persistently low and the FD is generally high in the deep slope of the central-west. This area is close to the warmer Norwegian Sea and is thereby regularly influenced by functionally similar Atlantic water species, especially in warm years (Dolgov et al. 2011). This results in high SR but low functional dispersion. For instance, many of the species found in the west, exemplified by the Atlantic herring Clupea harengus and the ribbon barracudina Arctozenus risso, are pelagic, feed on zooplankton, and are strong migrators. Thus, each contributes little to functional dispersion.

A given species may be of minor importance for local functional dispersion but still have a major impact on the global FD (i.e. for the entire Barents Sea). In this study, the capelin had the highest impact on the global FD, whereas the tolerance range traits had the strongest influence on FD estimates. The capelin shares many traits and to some degree overlaps spatially with species such as the herring and the ribbon barracudina. But because the capelin is distributed nearly throughout the Barents Sea, its global contribution to FD is more important than that of similar species with more restricted distributions.

\section{SUMMARY AND CONCLUSIONS}

This study shows that there is substantial spatial variation in FD of fish assemblages in the Barents Sea, partly associated with hydrographic characteristics known to influence fish community structure. Although persistent spatial patterns were identified, such as high FD in the central-west and low FD in the southeast, in some regions, such as the northern reaches of the sampled area, there was clear varia- 
tion between years. In the warmer years, 2007 to 2008, the FD increased in northern areas and decreased in the southeast, and we hypothesize that these FD patterns may become more common in years to come as a consequence of the predicted global environmental change. The functional dispersion revealed that species in the east rather persistently showed higher dissimilarities than species in the west. In terms of community functioning, high functional dispersion may compensate for a low SR, but it also implies that a local species loss would have a substantial impact on FD. We hypothesize that the observed patterns in FD reflect spatial variation in the ecosystems' way of functioning. To shed further light on marine ecosystem functioning and processes, we encourage future research programs to gather behavioral, life history and morphological traits with clear functional interpretation. We suggest that trait-based methods such as FD may constitute informative tools for future monitoring and management of marine fish communities.

Acknowledgements. This is a contribution to the Barents Sea Ecosystem Resilience under Global Environmental Change project funded by the Norwegian Research Council, contract no. 200793/S30. Thanks to C. Ottesen for providing trait information for rarely studied species. Thanks are also due to $\mathrm{M}$. Borit and T. de Lange Wenneck. Collaboration on the joint Norwegian-Russian ecosystem surveys between the IMR, Norway, and PINRO, Russia, made this study possible. M.G.'s research is partially supported by the Spanish Ministry of Economy and Competitiveness, grant no. MTM2012-37195. The comments from 3 anonymous reviewers are greatly acknowledged.

\section{LITERATURE CITED}

Blackburn TM, Petchey OL, Cassey P, Gaston KJ (2005) Functional diversity of mammalian predators and extinction in island birds. Ecology 86:2916-2923

Brander KM (2007) Global fish production and climate change. Proc Natl Acad Sci USA 104:19709-19714

Bundy A, Heymans JJ, Morissette L, Savenkoff C (2009) Seals, cod and forage fish: a comparative exploration of variations in the theme of stock collapse and ecosystem change in four northwest Atlantic ecosystems. Prog Oceanogr 81:188-206

Clarke KR, Warwick RM (1998) A taxonomic distinctness index and its statistical properties. J Appl Ecol 35: 523-531

Cressie NAC (1993) Statistics for spatial data. John Wiley \& Sons, New York, NY

Devictor V, Mouillot D, Meynard C, Jiguet F, Thuiller W, Mouquet N (2010) Spatial mismatch and congruence between taxonomic, phylogenetic and functional diversity: the need for integrative conservation strategies in a changing world. Ecol Lett 13:1030-1040

Díaz S, Cabido M (2001) Vive la différence: plant functional diversity matters to ecosystem processes. Trends Ecol
Evol 16:646-655

Dolgov AV, Johannesen E, Heino M, Olsen E (2010) Trophic ecology of blue whiting in the Barents Sea. ICES J Mar Sci 67:483-493

Dolgov AV, Johannesen E, Høynes Å (2011) Fish. Main species and ecological importance. In: Jacobsen T, Ozhigin VK (eds) The Barents Sea. Ecosystem, resources, management. Half a century of Russian-Norwegian cooperation. Tapir Academic Press, Trondheim, p 193-200

$>$ Faith DP (1992) Conservation evaluation and phylogenetic diversity. Biol Conserv 61:1-10

> Flynn DFB, Gogol-Prokurat M, Nogeire T, Molinari N and others (2009) Loss of functional diversity under land use intensification across multiple taxa. Ecol Lett 12:22-33

> Froese R, Binohlan C (2000) Empirical relationships to estimate asymptotic length, length at first maturity and length at maximum yield per recruit in fishes, with a simple method to evaluate length frequency data. J Fish Biol 56:758-773

Froese R, Pauly D (2011) FishBase. Available at www.fishbase.org

Furrer R, Nychka D, Sain S (2012) fields: tools for spatial data. R package version 6.6.3. Available at www.CRAN. R-project.org/package=fields

> Gower JC (1971) A general coefficient of similarity and some of its properties. Biometrics 27:857-874

> Halpern BS, Floeter SR (2008) Functional diversity responses to changing species richness in reef fish communities. Mar Ecol Prog Ser 364:147-156

> Hooper DU, Chapin FS III, Ewel JJ, Hector A and others (2005) Effects of biodiversity on ecosystem functioning: a consensus of current knowledge. Ecol Monogr 75:3-35

IPCC (Intergovernmental Panel on Climate Change) (1996) IPCC second assessment report: climate change 1995. Cambridge University Press, Cambridge

Johannesen E, Høines ÅS, Dolgov AV, Fossheim M (2012a) Demersal fish assemblages and spatial diversity patterns in the Arctic-Atlantic transition zone in the Barents Sea. PLoS ONE 7:e34924

Johannesen E, Ingvaldsen RB, Bogstad B, Dalpadado P and others (2012b) Changes in Barents Sea ecosystem state, 1970-2009: climate fluctuations, human impact, and trophic interactions. ICES J Mar Sci 69:880-889

Laliberté E, Legendre P (2010) A distance-based framework for measuring functional diversity from multiple traits. Ecology 91:299-305

Levin SA, Lubchenco J (2008) Resilience, robustness, and marine ecosystem-based management. Bioscience 58: $27-32$

Lewin-Koh NJ, Bivand R (2012) Maptools: tools for reading and handling spatial objects. $\mathrm{R}$ package version $0.8-$ 16. Available at www.CRAN.R-project.org/package $=$ maptools

Loeng H (1991) Features of the physical oceanographic conditions of the Barents Sea. Polar Res 10:5-18

> Loreau M, Naeem S, Inchausti P, Bengtsson J and others (2001) Biodiversity and ecosystem functioning: current knowledge and future challenges. Science 294:804-808

Mace GM, Gittleman JL, Purvis A (2003) Preserving the tree of life. Science 300:1707-1709

- Martins GM, Arenas F, Neto AI, Jenkins SR (2012) Effects of fishing and regional species pool on the functional diversity of fish communities. PLoS ONE 7:e44297.

Micheli F, Halpern BS (2005) Low functional redundancy in coastal marine assemblages. Ecol Lett 8:391-400 
Mouillot D, Dumay O, Tomasini JA (2007) Limiting similarity, niche filtering and functional diversity in coastal lagoon fish communities. Estuar Coast Shelf Sci 71: 443-456

Nakken O (1998) Past, present and future exploitation and management of marine resources in the Barents Sea and adjacent areas. Fish Res 37:23-35

Oksanen J, Blanchet FG, Kindt R, Legendre P and others (2011) vegan: community ecology package. R package version 1.17-12. Available at www.CRAN.Rproject.org/ package=vegan

Olsen E, Gjøsæeter H, Røttingen I, Dommasnes A, Fossum P, Sandberg P (2007) The Norwegian ecosystem-based management plan for the Barents Sea. ICES J Mar Sci 64: 599-602

Overland JE, Stabeno PJ (2004) Is the climate of the Bering Sea warming and affecting the ecosystem? Eos Trans Am Geophys Union 85:309-312

Ozhigin VK, Ingvaldsen RB, Loeng H, Boitsov VD, Karsakov AL (2011) The Barents Sea. In: Jacobsen T, Ozhigin VK (eds) The Barents Sea. Ecosystem, resources, management. Half a century of Russian-Norwegian cooperation. Tapir Academic Press, Trondheim, p 39-76

Pebesma EJ, Wesseling CG (1998) Gstat: a program for geostatistical modelling, prediction and simulation. Comput Geosci 24:17-31

Petchey OL, Gaston KJ (2002) Functional diversity (FD), species richness and community composition. Ecol Lett 5: 402-411

Petchey OL, Gaston KJ (2006) Functional diversity: back to basics and looking forward. Ecol Lett 9:741-758

Podani J, Schmera D (2006) On dendrogram-based measures of functional diversity. Oikos 115:179-185

R Development Core Team (2012) R: a language and environment for statistical computing. R Foundation for Statistical Computing, Vienna. Available at www.r-project. org

Rodrigues J (2009) The increase in the length of the ice-free season in the Arctic. Cold Reg Sci Technol 59:78-101

Editorial responsibility: Jake Rice,

Ottawa, Ontario, Canada
Stelzenmüller V, Maynou F, Martín P (2009) Patterns of species and functional diversity around a coastal marine reserve: a fisheries perspective. Aquat Conserv 19: 554-565

Tilman D (2001) Functional diversity. In: Levin SA (ed) Encyclopedia of biodiversity, Vol. 3. Academic Press, San Diego, CA, p 109-120

Tilman D, Knops J, Wedin D, Reich P, Ritchie M, Siemann E (1997) The influence of functional diversity and composition on ecosystem processes. Science 277:1300-1302

Villéger S, Mason NWH, Mouillot D (2008) New multidimensional functional diversity indices for a multifaceted framework in functional ecology. Ecology 89:2290-2301

Wadhams P (2012) Arctic ice cover, ice thickness and tipping points. Ambio 41:23-33

Wainwright PC (1994). Functional morphology as a tool in ecological research. In: Wainwright PC, Reilly SM (eds) Ecological morphology: integrative organismal biology.. University of Chicago Press, Chicago, IL, p 42-59

- Walker B, Kinzig A, Langridge J (1999) Plant attribute diversity, resilience, and ecosystem function: the nature and significance of dominant and minor species. Ecosystems 2:95-113

Wang M, Overland J (2009) A sea ice free summer Arctic within 30 years? Geophys Res Lett 36:L07502, doi:10. 1029/2009GL037820

> Weiher E, Keddy PA (1995) Assembly rules, null models, and trait dispersion: new questions from old patterns. Oikos 74:159-164

Wienerroither R, Johannesen E, Dolgov A, Byrkjedal I and others (2011) Atlas of the Barents Sea fishes. IMR/PINRO Joint Report Series 1-2011

> Wood SN (2000) Modelling and smoothing parameter estimation with multiple quadratic penalties. J R Stat Soc, B 62:413-428

Zeller D, Booth S, Pakhomov E, Swartz W, Pauly D (2011) Arctic fisheries catches in Russia, USA, and Canada: baselines for neglected ecosystems. Polar Biol 34:955-973

Submitted: March 6, 2013; Accepted: September 10, 2013

Proofs received from author(s): November 21, 2013 